\title{
Agreement Between Actual and Perceived Body Weight in Adolescents and Their Weight Control Behaviors
}

\author{
Sun Mi Shin* \\ Department of Nursing, Joongbu University, Geumsan, Korea
}

Background: To investigate the agreements between actual and perceived body weight status among adolescents and to identify the associations of disagreements with their weight control behaviors.

Methods: This study used the secondary data of a sample survey $(n=13,871)$ of the Seoul Student Health Examination among middle and high schools in 2010. Agreements between actual (underweight, normal, overweight, and obese, according to 2007 Korean National Growth Charts) and perceived body weight status (underweight, normal, overweight, and obese) were examined using Chi-square and Cohen's kappa agreement, and then multinomial logistic regression including gender, grade, and attempt of weight control or method of weight control was done.

Results: Agreements between actual and perceived body weight status were only $45.2 \%$, and disagreements were up to $54.8 \%$, including mild over- $(20.4 \%)$, severe over- $(1.8 \%)$, mild under- $(29.5 \%)$, and severe under-estimation (3.1\%). The kappa coefficient of agreement was only 0.19 . The odds ratios on severe over-estimated perception were $1.59(95 \% \mathrm{Cl}, 1.22-2.07)$ in female subjects, $1.78(95 \% \mathrm{Cl}, 1.36-2.34)$ in diet control behaviors, and $1.53(95 \% \mathrm{Cl}, 1.18-2.00)$ in exercise. The odds ratios on severe under-estimated perception were only 0.40 ( $95 \%$ $\mathrm{Cl}, 0.32-0.50)$ in female subjects but $5.77(95 \% \mathrm{Cl}, 3.68-9.06)$ in taking medication.

Conclusion: There were associations of body weight control behaviors with disagreements of actual and perceived weight status. Therefore, further study is needed to identify the weight disagreement-related factors and to promote the desired weight control behaviors for adolescents.

Key words: Adolescents, Agreements, Actual body weight, Perceived body weight, Weight control behaviors
Received October 31, 2015

Reviewed December 3, 2015

Accepted February 29, 2016

*Corresponding author

Sun Mi Shin

http://orcid.org/0000-0003-4040-6120

Department of Nursing, Joongbu

University, 201 Daehak-ro,

Chubu-myeon, Geumsan-gun,

Chungnam 32713, Korea

Tel: +82-41-750-6255

Fax: $+82-41-750-6416$

E-mail: healthteam@joongbu.ac.kr

\section{INTRODUCTION}

Obesity is a condition in which fat tissues accumulate excessive$1 y^{1,2}$, and it is increasingly common in wealthy modern societies. The increasing trend of childhood and adolescent obesity in particular is becoming more drastic. As of 2010, for example, obesity doubled in children and quadrupled in adolescents in the US over the past 3 decades. More than a third of American children and adolescents were found to be overweight or obese in 2012. ${ }^{3}$ In Korea also, the Seoul School Health Promotion Center conducted a
School Health Examination survey with a sample of students. The prevalence of child obesity was only about $2 \%$ in 1979 but hit $10 \%$ in 1997. The 2009 Korea National Health and Nutrition Examination Survey reported that the prevalence of obesity was $6.4 \%$ in children aged 2 to 5 years old, $7.3 \%$ in those aged 6 to 11, and $11.3 \%$ in those aged 12 to 18 ; in short, it increased with age. ${ }^{4}$

Actual weight status and perceived weight can differ. This is because individuals may evaluate their weight based on comparison of oneself with others, or with what society has set as weight standards, rather than based on their actual weight status. Some prece-

Copyright (C) 2017 Korean Society for the Study of Obesity

(a) This is an Open Access article distributed under the terms of the Creative Commons Attribution Non-Commercial License (http://creativecommons.org/licenses/by-nc/4.0/) which permits unrestricted non-commercial use, distribution, and reproduction in any medium, provided the original work is properly cited. 
dent studies suggested that female students, white Americans, and Asian Americans perceived themselves as severely overweight in comparison to African Americans considering their actual body weight status. ${ }^{5,6}$

An exact perception of weight based on actual body weight status is highly important in obesity management and prevention. Depending on how individuals perceive their body weight, individual behaviors for obesity prevention or management may vary. If one overestimates one's weight, one will probably show weight control behaviors such as diet and workout regime or medicine intake. In this case, unnecessary control behaviors, or weight control behaviors that are harmful to health ${ }^{7-9}$, may disturb the desired nutritional balance of the body or cause waste of time and money.

Contrarily, one might evaluate oneself as having normal weight or underweight while being overweight or obese in reality. This may cause one not to try healthy weight control through exercise or diet or to start it too late ${ }^{7-9}$, bringing about serious problems including complications, cardiovascular diseases, and diabetes caused by obesity. It is possible to predict the involvement of weight control behaviors through an evaluation of weight status perceived by individuals. ${ }^{10,11}$ Therefore, this study investigated the agreement between actual and perceived body weight status among middle and high school students in the city of Seoul. It aimed to identify "mild overestimation," "severe overestimation," "mild underestimation," and "severe underestimation" of body weight as well as weight control behaviors.

\section{METHODS}

\section{Study material and subjects}

This is a cross-sectional descriptive study using secondary data to examine the level of agreement between actual and perceived body weight status and weight control behaviors in the adolescent population living in Seoul. The secondary data used in this study were from a sample survey of School Health Examination conducted by Seoul School Health Promotion Center according to the School Health Law and School Health Examinations Rules. ${ }^{12}$ Study subjects were 7 th to 12 th grade students at middle and high schools in 2010 selected through random sampling considering the population size (the numbers of schools and classes) and commu- nity conditions. The number of sample students was 14,470 . Among these, 599 students who did not give a response on perceived body weight status were excluded, and the total number of subjects for analysis was 13,871 , which was $95.9 \%$ of the raw data.

\section{Data collection and ethical consideration}

The sample survey data were collected from middle and high schools that had been selected as a sample for the city of Seoul according to the School Health Examination Sample Survey Guidelines ${ }^{12}$ in order to survey the health status of the school-age population. The survey was conducted for 2 months starting in April of 2010. Height, weight, vision, and hearing were examined. For the survey questionnaire to examine symptoms and health behaviors during the last month, a form suggested by the Ministry of Education and Science Technology ${ }^{12}$ was used, and it was collected after respondents self-reported.

I received a request from the Seoul School Health Promotion Center to analyze the raw data and gained approval for publishing contents necessary for the development of school health in the form of study results for journals through further analysis. The results were analyzed per group, and individual identification variables such as name, school, classroom number, or contact number were completely eliminated from analysis variables to ensure protection of personal data.

\section{Measurement variables}

The measurement variables used in this study were general characteristics including gender and grade and other variables including obesity rate indicating actual body weight status, perceived body weight status, attempt for weight control, and method of weight control (diet, exercise, and medication). Actual body weight was measured by comparing the body mass index $(\mathrm{BMI})\left(\mathrm{kg} / \mathrm{m}^{2}\right)$ calculated using measured height $(\mathrm{cm})$ and weight $(\mathrm{kg})$ to the 2007 Standard Growth Chart for Children and Adolescents ${ }^{12}$ by the Korean Pediatric Society. Subjects were classified as "underweight" if the figure was below the 5 th percentile, "normal" if between 5 th and 85th, "overweight" if between 85th and 95th, and "obese" if over 95th or if the BMI was 25 or higher, which is the standard for adult obesity.

The perceived body weight was measured based on the answers "I am very skinny," 'I am a little skinny," "I am normal," “I am a little bit 
fat," and "I am very fat" to the question "What do you think of your body weight compared to your friends?" This study matched "I am very skinny" and "I am a little skinny" with "underweight" in the obesity rate, "I am normal" with "normal weight," "I am a little bit fat" with "overweight," and "I am very fat" with "obese" in order to identify the degree of agreement with actual obesity rate. In the questions to verify the weight control experience, if the respondents answered "yes" to the attempt to lose weight, it was marked as "attempted," and if they answered "yes" to any of the weight control methods of diet, medication, and exercise, it was considered as having an experience for each item and was established as a new variable.

\section{Analysis method}

SAS 9.4 (SAS Inc., Cary, NC, USA) was used for the analysis. The participant characteristics were examined through a descriptive analysis, and the agreement of actual body weight status (obesity rate) and perceived body weight status was assessed using the Cohen's kappa coefficient of agreement. If the 2 variables agreed on a contingency table of actual and perceived body weight status, it was classified as "agreed." In case of disagreement, it was classified into the following 4 types: When the perceived body weight status was one level higher than actual body weight status, it was reclassified as "mild overestimation"; when 2 levels higher, as "severe overestimation"; when one level lower, as "mild underestimation"; and when 2 levels lower, as "severe underestimation." The distribution of each category was verified with a Chi-square test.

The odds ratios of "mild overestimation" and "severe overestimation" and "mild underestimation" and "severe underestimation" were then examined using multinomial logistic regression concerning gender, grade, and weight control behaviors. In the entire analysis, missing data in each variable were eliminated before suggesting the final values, and it was considered statistically significant when the significance level was less than 0.05 .

\section{RESULTS}

\section{Demographic and obesity-related characteristics of study subjects}

Among the 13,871 subjects, male students accounted for 54.6\% and female students $45.4 \%$. In the obesity rate based on BMI, $4.4 \%$ were underweight, $76.1 \%$ were normal weight, $4.7 \%$ were overweight, and $14.7 \%$ were obese. In terms of gender, there were more overweight female students and more obese male students $(P<$ 0.001).

In terms of perceived body weight according to gender, male and female students showed a difference accounting for $31.4 \%$ and $19.9 \%$, respectively, for being skinny. Male students who perceived themselves as a little bit fat and very fat accounted for $25.7 \%$ and $6.1 \%$, respectively, whereas female students accounted for $33.8 \%$ and $8.1 \%(P<0.001)$.

Among the surveyed students, $52.7 \%$ tried to control their weight. By gender, more female students made an attempt, accounting for $62.1 \%$, than male students, accounting for $44.9 \%$ $(P<0.001)$. Students who tried diet for weight control accounted for $30.9 \%$. By gender, the difference showed that $19.0 \%$ of male students and $45.0 \%$ female students tried the behavior $(P<0.001)$. Two percent tried medication for weight control, and the difference was $1.3 \%$ in male students and $2.9 \%$ in female students $(P<0.001)$. Finally, $40.8 \%$ of students controlled weight through exercise. The difference was $34.7 \%$ in male students and $48.0 \%$ in female students $(P<0.001)$ (Table 1$)$.

\section{Agreement between actual and perceived body weight status}

The percentile of agreement between the actual and perceived body weight status was examined. The "agreement" case of actual "underweight" and perceived "skinny" accounted for $78.1 \%$, the "normal" case of actual "normal" and perceived "normal" for $44.9 \%$, the case of actual "overweight" and perceived "a little bit fat" for $61.5 \%$, and the case of actual "obese" and perceived "very fat" for $31.8 \%$. The kappa coefficient was 0.19 (95\% CI, 0.18-0.20), and the agreement level was weak (Table 2). ${ }^{13}$

\section{Comparison of agreement and disagreement in body weight status according to participant characteristics}

The actual and perceived body weight statuses were examined based on the participant characteristics. The agreement of male students was $42.3 \%$, which was lower than that of female students at $48.7 \%(P<0.001)$. The grade with the highest agreement level was middle school 7 th grade at $47.9 \%$, and the lowest was middle 
Table 1. Demographic and obesity-related characteristics

\begin{tabular}{|c|c|c|c|c|c|c|c|}
\hline Classification & & & Total & Male & Female & Chi-square & $P$ \\
\hline Subjects & & & 13,871 & $7,568(100)$ & $6,303(100)$ & & \\
\hline \multirow[t]{6}{*}{ Grade } & 7th & & 2,345 & $1,314(17.4)$ & $1,031(16.4)$ & 52.45 & $<0.001$ \\
\hline & 8th & & 2,232 & $1,246(16.5)$ & $986(15.6)$ & & \\
\hline & 9th & & 2,372 & $1,410(18.6)$ & 962 (15.3) & & \\
\hline & 10th & & 2,428 & $1,215(16.1)$ & $1,213(19.2)$ & & \\
\hline & 11th & & 2,193 & $1,140(15.1)$ & $1,053(16.7)$ & & \\
\hline & 12th & & 2,301 & $1,243(16.4)$ & $1,058(16.8)$ & & \\
\hline \multirow[t]{4}{*}{ Actual body weight status } & Underweight & & 611 & $283(3.7)$ & $328(5.2)$ & 353.35 & $<0.001$ \\
\hline & Normal & & 10,561 & $5,685(75.1)$ & $4,876(77.4)$ & & \\
\hline & Overweight & & 657 & $194(2.6)$ & $463(7.4)$ & & \\
\hline & Obese & & 2,042 & $1,406(18.6)$ & $636(10.1)$ & & \\
\hline \multirow[t]{4}{*}{ Perceived body weight status } & Underweight (skinny) & & 3,632 & 2,377 (31.4) & $1,255(19.9)$ & 271.28 & $<0.001$ \\
\hline & Normal & & 5,197 & 2,786 (36.8) & 2,411 (38.3) & & \\
\hline & Overweight (a little bit fat) & & 4,075 & $1,947(25.7)$ & $2,128(33.8)$ & & \\
\hline & Obese (very fat) & & 967 & $458(6.1)$ & $509(8.1)$ & & \\
\hline \multirow[t]{2}{*}{ Attempt(s) to lose weight } & Yes & & 7,307 & $3,396(44.9)$ & $3,911(62.1)$ & 407.01 & $<0.001$ \\
\hline & No & & 6,564 & $4,172(55.1)$ & 2,392 (38.0) & & \\
\hline \multirow[t]{6}{*}{ Methods of weight control } & Diet & Yes & & $1,441(19.0)$ & $2,839(45.0)$ & 1089.72 & $<0.001$ \\
\hline & & No & & $6,127(81.0)$ & $3,464(55.0)$ & & \\
\hline & Medication & Yes & & $95(1.3)$ & $182(2.9)$ & 46.81 & $<0.001$ \\
\hline & & No & & $7,473(98.7)$ & 6,121 (97.1) & & \\
\hline & Exercises & Yes & & $2,628(34.7)$ & $3,026(48.0)$ & 251.31 & $<0.001$ \\
\hline & & No & & $4,940(65.3)$ & $3,277(52.0)$ & & \\
\hline
\end{tabular}

Data shown are number (percent) by descriptive and Chi-square.

Grades 7th, 8th, and 9th are middle school students.

Grades 10th, 11th, and 12th are high school students.

Table 2. Agreement percent between actual and perceived body weight status

\begin{tabular}{lcccc}
\hline \multirow{2}{*}{ Perceived body weight status } & \multicolumn{4}{c}{ Actual body weight status } \\
\cline { 2 - 4 } & Underweight $(\mathrm{n}=611)$ & Normal $(\mathrm{n}=10,561)$ & Overweight $(\mathrm{n}=657)$ & Obese $(\mathrm{n}=2,042)$ \\
\hline Underweight (skinny), $\mathrm{n}=3,632$ & 78.1 & 28.1 & 7.8 & 6.8 \\
Normal, $\mathrm{n}=5,197$ & 17.8 & 44.9 & 17.4 & 11.5 \\
Overweight (a little bit fat), $\mathrm{n}=4,075$ & 3.6 & 24.9 & 61.5 & 49.9 \\
Obese (very fat), $\mathrm{n}=967$ & 0.5 & 2.1 & 13.4 & 31.8 \\
\hline
\end{tabular}

Data shown are agreement percent with Kappa Coefficient.

school 9th grade at $42.6 \%(P<0.001)$.

"Mild overestimation" and "severe overestimation" were higher in female students, accounting for $27.1 \%$ and $2.5 \%$, respectively, than in male students, accounting for $14.8 \%$ and $1.2 \%$; they were higher in higher grades with $17.0 \%$ and $0.9 \%$, respectively, in middle school 7th graders, $19.3 \%$ and $1.8 \%$ in middle school 9th graders, and $22.8 \%$ and $2.4 \%$ in high school 12 th graders. They were higher in students who attempted weight control, accounting for $27.1 \%$ and $2.3 \%$, respectively, and those who did not, accounting for $13.0 \%$ and $1.2 \%$; in students who controlled their diet, accounting for $30.5 \%$ and $2.9 \%$, than in those who did not, accounting for $15.9 \%$ and $1.3 \%$; and in students who exercised, accounting for $27.8 \%$ and $2.5 \%$, than those who did not, accounting for $15.3 \%$ and $1.4 \%(P<0.001)$.

"Mild underestimation" and "severe underestimation" were found in $39.0 \%$ and $9.8 \%$, respectively, in students who took medication for weight control, higher than the percentiles $29.4 \%$ and $2.9 \%$ of those who did not $(P<0.001)$ (Table 3$)$. 
Table 3. Agreement and disagreement percent between actual and perceived body weight by demographic and obesity-related characteristics

\begin{tabular}{|c|c|c|c|c|c|c|c|c|c|c|}
\hline \multirow{2}{*}{ Classification } & & & \multirow[b]{2}{*}{ Subjects } & \multirow[b]{2}{*}{$\begin{array}{c}\text { Agreement } \\
(n=6,271)\end{array}$} & \multicolumn{4}{|c|}{ Disagreement } & \multirow[b]{2}{*}{ Chi-square } & \multirow[b]{2}{*}{$P$} \\
\hline & & & & & $\begin{array}{l}\text { Mild over- } \\
\text { estimation } \\
(\mathrm{n}=2,827)\end{array}$ & $\begin{array}{l}\text { Severe over- } \\
\text { estimation } \\
(n=251)\end{array}$ & $\begin{array}{c}\text { Mild under- } \\
\text { estimation } \\
(n=4,098)\end{array}$ & $\begin{array}{c}\text { Severe under- } \\
\text { estimation } \\
(n=424)\end{array}$ & & \\
\hline Total & & & 13,871 & 45.2 & 20.4 & 1.8 & 29.5 & 3.1 & & \\
\hline \multirow[t]{2}{*}{ Gender } & Male & & 7,568 & 42.3 & 14.8 & 1.2 & 37.7 & 4.0 & 738.20 & $<0.001$ \\
\hline & Female & & 6,303 & 48.7 & 27.1 & 2.5 & 19.7 & 2.0 & & \\
\hline \multirow[t]{6}{*}{ Grade } & 7th & & 2,345 & 47.9 & 17.0 & 0.9 & 30.7 & 3.5 & 105.21 & $<0.001$ \\
\hline & 8th & & 2,232 & 46.1 & 18.2 & 1.5 & 31.2 & 3.0 & & \\
\hline & 9th & & 2,372 & 42.6 & 19.3 & 1.8 & 33.0 & 3.3 & & \\
\hline & 10th & & 2,428 & 44.0 & 21.9 & 1.8 & 29.1 & 3.2 & & \\
\hline & 11th & & 2,193 & 44.1 & 23.2 & 2.5 & 28.0 & 2.2 & & \\
\hline & 12th & & 2,301 & 46.6 & 22.8 & 2.4 & 25.2 & 3.0 & & \\
\hline \multirow[t]{2}{*}{ Attempt(s) to lose weight } & Yes & & 7,307 & 44.4 & 27.1 & 2.3 & 22.9 & 3.3 & 594.82 & $<0.001$ \\
\hline & No & & 6,564 & 46.1 & 13.0 & 1.2 & 36.9 & 2.8 & & \\
\hline \multirow[t]{6}{*}{ Methods of weight control } & Diet & Yes & 4,280 & 43.3 & 30.5 & 2.9 & 20.7 & 2.7 & 521.23 & $<0.001$ \\
\hline & & No & 9,591 & 46.0 & 15.9 & 1.3 & 33.5 & 3.2 & & \\
\hline & Medication & Yes & 277 & 32.5 & 16.3 & 2.5 & 39.0 & 9.8 & 63.22 & $<0.001$ \\
\hline & & No & 13,594 & 45.5 & 20.5 & 1.8 & 29.4 & 2.9 & & \\
\hline & Exercises & Yes & 5,654 & 45.1 & 27.8 & 2.5 & 21.6 & 3.0 & 482.28 & $<0.001$ \\
\hline & & No & 8,217 & 45.3 & 15.3 & 1.4 & 35.0 & 3.1 & & \\
\hline
\end{tabular}

Data shown are percent of agreement and disagreement type by descriptive and Chi-square. Grades 7th, 8th, and 9th are middle school students.

Grades 10th, 11th, and 12th are high school students.

\section{Factors related to the disagreement between actual and} perceived body weight status

For the subjects with disagreed actual and perceived body weight statuses, the variables influencing "mild overestimation," "severe overestimation," "mild underestimation," and "severe underestimation" were examined through multinomial logistic regression.

In Model 1, the odds ratio was examined after introducing gender, grade, and weight control attempt to the model. The respective odds ratio of "mild overestimation" and "severe overestimation" 1.43 (95\% CI, 1.31-1.57) and 1.59 (95\% CI, 1.22-2.07) in female students; 1.25 (95\% CI, 1.06-1.46) and 2.09 (95\% CI, 1.24-3.53) in middle school 9th graders; 1.35 (95\% CI, 1.15-1.58) and 1.97 (95\% CI, 1.17-3.32) in high school 10th graders; 1.41 (95\% CI, 1.20-1.65) and 2.77 (95\% CI, 1.68-4.59) in high school 11th graders; and 1.38 (95\% CI, 1.18-1.62) and 2.62 (95\% CI, 1.59-4.33) in high school 12th graders. The ratios were 2.05 (95\% CI, 1.87-2.26) and 1.81 (95\% CI, 1.38-2.38) when weight control was attempted respectively.

In Model 2, the weight control methods of diet, medication, and exercise were newly introduced in place of weight control attempt in Model 1. The odds ratio of "mild overestimation" and "severe overestimation" was also higher as the grade got higher, just as in Model 1. For diet control, the odd ratios were 1.66 (95\% CI, 1.501.83 ) and 1.78 (95\% CI, 1.36-2.34) when controlled respectively and 1.58 (95\% CI, 1.44-1.74) and 1.53 (95\% CI, 1.18-2.00) when exercise was performed, respectively Therefore, it was found that it was more likely for students on a diet and those controlling weight through exercise to overestimate their body weight. Conversely, in the case of taking medication, the odds ratios of "mild underestimation" and "severe underestimation" were 2.29 (95\% CI, 1.723.07 ) and 5.77 (95\% CI, 3.68-9.06), respectively. It was found that students who did take some medication for weight control was more likely to underestimate their body weight (Table 4).

\section{DISCUSSION}

Obesity continues to grow in modern societies, and the trend of adolescent obesity is increasing at a more rapid rate. ${ }^{14}$ Therefore, various health improvement strategies should be designed to manage obesity. In this context, this study was initiated to explore the degree of agreement between actual and perceived body weight 
Table 4. Factors of disagreement between actual and perceived body weight status by multinomial logistic regression

\begin{tabular}{|c|c|c|c|c|c|c|c|}
\hline \multirow{2}{*}{ Model } & \multirow{2}{*}{ Classification } & & & \multicolumn{4}{|c|}{ Disagreement } \\
\hline & & & & Mild over-estimation & Severe over-estimation & Mild under-estimation & Severe under-estimation \\
\hline \multirow[t]{10}{*}{ Model 1} & \multirow[t]{2}{*}{ Gender } & \multicolumn{2}{|l|}{ Male } & 1.0 & 1.0 & 1.0 & 1.0 \\
\hline & & \multicolumn{2}{|l|}{ Female } & $1.43(1.31-1.57)$ & $1.59(1.22-2.07)$ & $0.48(0.44-0.52)$ & $0.41(0.33-0.51)$ \\
\hline & \multirow[t]{6}{*}{ Grade } & \multicolumn{2}{|l|}{7 th } & 1.0 & 1.0 & 1.0 & 1.0 \\
\hline & & \multicolumn{2}{|l|}{ 8th } & $1.09(0.93-1.29)$ & $1.66(0.96-2.86)$ & $1.06(0.93-1.22)$ & $0.86(0.62-1.21)$ \\
\hline & & \multicolumn{2}{|l|}{ 9th } & $1.25(1.06-1.46)$ & $2.09(1.24-3.53)$ & $1.19(1.04-1.36)$ & $1.02(0.74-1.40)$ \\
\hline & & \multicolumn{2}{|l|}{ 10th } & $1.35(1.15-1.58)$ & $1.97(1.17-3.32)$ & 1.07 (0.94-1.23) & $1.03(0.75-1.42)$ \\
\hline & & \multicolumn{2}{|l|}{ 11th } & $1.41(1.20-1.65)$ & $2.77(1.68-4.59)$ & $1.02(0.89-1.17)$ & $0.69(0.48-1.00)$ \\
\hline & & \multicolumn{2}{|l|}{ 12th } & $1.38(1.18-1.62)$ & $2.62(1.59-4.33)$ & $0.84(0.73-0.96)$ & $0.87(0.63-1.22)$ \\
\hline & \multirow[t]{2}{*}{ Attempt(s) to lose weight } & \multicolumn{2}{|l|}{ No } & 1.0 & 1.0 & 1.0 & 1.0 \\
\hline & & \multicolumn{2}{|l|}{ Yes } & $2.05(1.87-2.26)$ & $1.81(1.38-2.38)$ & $0.71(0.65-0.77)$ & $1.35(1.11-1.65)$ \\
\hline \multirow[t]{14}{*}{ Model 2} & \multirow[t]{2}{*}{ Gender } & \multicolumn{2}{|l|}{ Male } & 1.0 & 1.0 & 1.0 & 1.0 \\
\hline & & \multicolumn{2}{|l|}{ Female } & $1.32(1.20-1.45)$ & $1.40(1.07-1.84)$ & $0.48(0.44-0.52)$ & $0.40(0.32-0.50)$ \\
\hline & \multirow[t]{6}{*}{ Grade } & \multicolumn{2}{|l|}{7 th } & 1.0 & 1.0 & 1.0 & 1.0 \\
\hline & & \multicolumn{2}{|l|}{ 8th } & $1.08(0.92-1.27)$ & $1.63(0.95-2.81)$ & $1.06(0.93-1.22)$ & $0.86(0.62-1.21)$ \\
\hline & & \multicolumn{2}{|l|}{ 9th } & $1.22(1.04-1.44)$ & $2.03(1.20-3.43)$ & $1.19(1.04-1.36)$ & $1.01(0.74-1.40)$ \\
\hline & & \multicolumn{2}{|l|}{ 10th } & $1.29(1.10-1.50)$ & $1.86(1.10-3.14)$ & $1.07(0.94-1.23)$ & $1.02(0.74-1.40)$ \\
\hline & & \multicolumn{2}{|l|}{ 11th } & $1.37(1.17-1.60)$ & $2.65(1.60-4.38)$ & $1.02(0.88-1.17)$ & $0.70(0.49-1.02)$ \\
\hline & & \multicolumn{2}{|l|}{ 12th } & $1.35(1.15-1.58)$ & $2.54(1.53-4.19)$ & $0.83(0.72-0.95)$ & $0.87(0.62-1.21)$ \\
\hline & \multirow[t]{6}{*}{ Methods of weight control } & \multirow[t]{2}{*}{ Diet } & No & 1.0 & 1.0 & 1.0 & 1.0 \\
\hline & & & Yes & $1.66(1.50-1.83)$ & $1.78(1.36-2.34)$ & $0.87(0.79-0.96)$ & $1.07(0.85-1.36)$ \\
\hline & & \multirow[t]{2}{*}{ Medication } & No & 1.0 & 1.0 & 1.0 & 1.0 \\
\hline & & & Yes & $0.91(0.63-1.31)$ & $1.57(0.72-3.46)$ & $2.29(1.72-3.07)$ & $5.77(3.68-9.06)$ \\
\hline & & \multirow[t]{2}{*}{ Exercise } & No & 1.0 & 1.0 & 1.0 & 1.0 \\
\hline & & & Yes & $1.58(1.44-1.74)$ & $1.53(1.18-2.00)$ & $0.67(0.62-0.74)$ & 1.04 (0.85-1.28) \\
\hline
\end{tabular}

Data shown are odds ratio (95\% Cl) adjusted for gender, grade and attempt to lose weight (model 1) or methods of weight control (model 2) by multinomial logistic regression. Grades 7th, 8th, and 9th are middle school students.

Grades 10th, 11th, and 12th are high school students.

status and the relationship between body weight perception and obesity control behaviors.

Adolescents, who are more sensitive to their appearances than any other age group, tended to perceive their weight by comparing it to that of others rather than their actual body weight status ${ }^{1,3}$, and their weight control behaviors varied depending on how they perceived their weight. In other words, they were performing behaviors to prevent or manage obesity when they perceived their weight as excessive. ${ }^{10,11}$ Therefore, it will be possible to predict the involvement of weight control behaviors according to their weight perception. The weight control behaviors of adolescents based on their weight perception are particularly important as these may shape their habitual behaviors, which may continue into adulthood.

The rate of agreement between actual and perceived body weight status was $45.2 \%$, and the disagreement rate was $54.8 \%$. In a study on the Korean adult population, the agreement of obesity and body-shape perception was $74.9 \%$, and disagreement was $25.1 \% .{ }^{15}$ Thus, the disagreement was higher in adolescents, and it is necessary to emphasize more precise weight perception among adolescents. In case of disagreement, it derives from underestimating or overestimating one's own weight. In this study, "mild overestimation" was found in $20.4 \%$, and "severe overestimation" was found in $1.8 \%$. "Mild underestimation" was found in $29.5 \%$, and "severe underestimation" was found in $3.1 \%$. The percentage of subjects who perceived themselves as underweight was higher than that of those who considered themselves overweight. This was quite different from some precedent studies on adolescents, which suggested that adolescents perceived themselves more as overweight even though they were normal.9,16

With regard to the agreement of actual and perceived body 
weight status in this study, underweight-skinny agreement was found in $78.1 \%$, normal weight-normal $44.9 \%$, overweight-a little fat $61.5 \%$, and obese-very fat $31.8 \%$. The levels of agreement were relatively higher in underweight and overweight, and those of normal and obese were relatively lower. These results differ from those of previous studies ${ }^{5}$ in which the level of agreement was higher in overweight or obese adolescents. ${ }^{5}$ Therefore, health improvement strategies targeting adolescents living in Seoul should design health education methods that help them perceive themselves as normal when their weight is normal and obese when their weight is obese.

In precedent studies, female students perceived their body weight as fat more than male students $\mathrm{did}^{5,6}$, and they considered being skinny as ideal. ${ }^{17}$ In this study (Model 2), the odds ratio of "mild overestimation" and "severe over estimation" was 1.32 (95\% CI, $1.20-1.45)$ and 1.40 (95\% CI, 1.07-1.84) in female students, respectively. Conversely, when it comes to underestimation that perceives the body weight as less than what it is, the odds ratios of "mild underestimation" and "severe underestimation" was 0.48 (95\% CI, $0.44-0.52$ ) and 0.40 (95\% CI, 0.32-0.50) in female students, respectively, in accordance with the precedent studies.

In previous studies, students perceived their body weight more precisely as they got older. ${ }^{11}$ In this study, however, the agreement of students ranging from middle school 7th grade to high school 12th grade was highest at $47.9 \%$ in the 7 th graders and lowest at $42.6 \%$ in the 9 th graders. It rose again to $46.6 \%$ in the 12 th graders, and no specific trend of increase or decrease in the precise perception along the grades was observed. However, "overestimation" did show an increase from middle school 7th grade through high school 11th grade, ranging from $17.0 \%$ to $18.2 \%, 19.3 \%, 21.9 \%$, and 23.2\%. "Severe overestimation" exhibited an increasing trend from the middle school 7th grade through high school 11th grade, ranging from $0.9 \%$ to $1.5 \%, 1.8 \%, 1.8 \%$, and $2.5 \%$.

Individuals who perceived their normal weight as overweight or obese showed more behaviors harmful to health such as unnecessary weight control, or unhealthy methods, including fasting, use of an appetite suppressant and diuretic, or smoking. ${ }^{7-9}$ Among the students in this study who had tried to control diet to lose weight, the odds ratio of "mild overestimation" was 1.66 (95\% CI, 1.501.83), and that of "severe overestimation" was 1.78 (95\% CI, 1.362.34). Among those who tried to lose weight through exercise, the odds ratio of "mild overestimation" was 1.58 (95\% CI, 1.44-1.74), and that of "severe overestimation" was 1.53 (95\% CI, 1.18-2.00). When students perceived their body weight as higher than what their actual BMI measured, they tried to control their body weight, and the main methods applied were diet and exercise.

"Mild underestimation" and "severe underestimation" were more frequent among middle school students than among high school students, and the odds ratio of "mild underestimation" was particularly high at 1.19 (95\% CI, 1.04-1.36) in middle school 9th graders than in 7 th graders. Among the students who were taking medication for weight control, the odds ratios of "mild underestimation" and "severe underestimation" were 2.29 (95\% CI, 1.72-3.07) and 5.77 (95\% CI, 3.68-9.06), respectively, and it is difficult to explain the reason in this study of a cross-sectional design. It is possible that the individuals changed their perception to underweight as actual body weight decreased through taking medication, or they may have a positive type of personality and trust the effect of the medication.

In previous studies, however, negative effects were observed such as not actively participating in weight control behaviors when the adolescents underestimated their body weight from actual overweight or obese status. ${ }^{16,18}$ It is necessary to enhance health education and counseling so that students can perceive their precise body weight, more for middle school students than for high school students, and for those who take medication. Additionally, the effectiveness of medication for diet and the association between medication, diet, and exercise should be explored further in future studies.

The conclusion and implications of this study are as follows. First, there was quite a difference between actual and perceived body weight among adolescents in Seoul, and there were differences between subjects whose perception agreed and those whose perception disagreed in their obesity-related behaviors such diet, exercise, and medication. Therefore, it is recommended for future studies to verify differences in the physiological health of agreed and disagreed students in order to assess the rationality of their obesity control behaviors. Second, female students overestimated their body weight more than male students, and the degree of "mild overestimation" and "severe overestimation" increased with grade. This is probably because students are largely influenced by their peer groups or the preference of society, and, thus, it is necessary to raise awareness further on the importance of healthy body weight 
perception during adolescence. Third, it was found that the students engaged in diet and exercise more, which were considered active obesity-related behaviors, when they perceived their body weight as "overweight" or "severely overweight." Contrarily, those who perceived their body weight as "mild underestimated weight" or "severely underestimated weight" took medication to a larger extent. Therefore, it is necessary to help them with a precise perception of body weight upon visits to health centers through routine measurement of height and weight and expert counseling.

The limitations and values of this study are as follows. First, this study yielded limited results as it utilized limited variables from secondary data of middle and high school students living in Seoul. However, it is valuable to examine the degree of agreement between the actual and perceived body weight status of students in one of the most representative cities in Korea. Second, various precedent studies have researched actual and perceived body weight. This study is distinguished from the majority of domestic precedents in that it identified and analyzed subjects with extreme disagreement who require more attention in terms of obesity control. While the majority of secondary data from domestic sample surveys are associated with BMI evaluation ${ }^{19-21}$ through self-reporting by subjects themselves, the body weights of the subjects used in this study were measured using a standardized tool and measurement method. Therefore, this study is valued for the precision in its evaluating the degree of agreement.

\section{CONFLICTS OF INTEREST}

The author declares no conflict of interest.

\section{ACKNOWLEDGMENTS}

I sincerely appreciate the kind assistance of the former medical provincial fourth grade official, Hee-Woo Lee, M.D., who allowed me to use the data of the Seoul School Health Promotion Center, which made this study possible.

\section{REFERENCES}

1. Daniels SR, Arnett DK, Eckel RH, Gidding SS, Hayman LL,
Kumanyika S, et al. Overweight in children and adolescents: pathophysiology, consequences, prevention, and treatment. Circulation 2005;111:1999-2012.

2. Krebs NF, Himes JH, Jacobson D, Nicklas TA, Guilday P, Styne D. Assessment of child and adolescent overweight and obesity. Pediatrics 2007;120 Suppl 4:S193-228.

3. Ogden CL, Carroll MD, Kit BK, Flegal KM. Prevalence of childhood and adult obesity in the United States, 2011-2012. JAMA 2014;311:806-14.

4. Park JY. Prevalence of overweight and obesity in Korean children: the results of Korean children-adolescent cohort study, 2005-2010. Public Health Weekly Report, KCDC 2011;47: 857-62.

5. Martin MA, Frisco ML, May AL. Gender and race/ethnic differences in inaccurate weight perceptions among U.S. adolescents. Womens Health Issues 2009;19:292-9.

6. Park H, Lee H. Wanting extremely low BMI may be associated with higher depression and undesirable dietary habits in high school girls who were not overweight. Korean J Community Nutr 2013;18:344-53.

7. Felts WM, Parrillo AV, Chenier T, Dunn P. Adolescents' perceptions of relative weight and self-reported weight-loss activities: analysis of 1990 YRBS (Youth Risk Behavior Survey) national data. J Adolesc Health 1996;18:20-6.

8. Neumark-Sztainer D, Wall M, Eisenberg ME, Story M, Hannan PJ. Overweight status and weight control behaviors in adolescents: longitudinal and secular trends from 1999 to 2004. Prev Med 2006;43:52-9.

9. Talamayan KS, Springer AE, Kelder SH, Gorospe EC, Joye KA. Prevalence of overweight misperception and weight control behaviors among normal weight adolescents in the United States. ScientificWorldJournal 2006;6:365-73.

10. Edwards NM, Pettingell S, Borowsky IW. Where perception meets reality: self-perception of weight in overweight adolescents. Pediatrics 2010;125:e452-8.

11. Foti K, Lowry R. Trends in perceived overweight status among overweight and nonoverweight adolescents. Arch Pediatr Adolesc Med 2010;164:636-42.

12. Ministry of Education. Manual of school health examination standard survey, 2009-2011. Seoul: Ministry of Education; 2009. 
13. Sierra F, Cárdenas A. Evidence-based medicine (EBM) in practice: agreement between observers rating esophageal varices: how to cope with chance? Am J Gastroenterol 2007;102: 2363-6.

14. Chung AE, Perrin EM, Skinner AC. Accuracy of child and adolescent weight perceptions and their relationships to dieting and exercise behaviors: a NHANES study. Acad Pediatr 2013; 13:371-8.

15. Chun IA, Ryu SY, Park J, Han MA, Choi SW, Ko DS. The associations between discordance of body image and physical activities among adults aged 19 to 64 years: based on the data from 2010 community health survey. Korean J Obes 2014;23: 274-80.

16. Strauss RS. Self-reported weight status and dieting in a crosssectional sample of young adolescents: National Health and Nutrition Examination Survey III. Arch Pediatr Adolesc Med 1999;153:741-7.

17. Alwan H, Viswanathan B, Paccaud F, Bovet P. Is accurate per- ception of body image associated with appropriate weightcontrol behavior among adolescents of the Seychelles. J Obes 2011;2011:817242.

18. Goodman E, Hinden BR, Khandelwal S. Accuracy of teen and parental reports of obesity and body mass index. Pediatrics 2000;106:52-8.

19. Park E. Overestimation and underestimation: adolescents' weight perception in comparison to BMI-based weight status and how it varies across socio-demographic factors. J Sch Health 2011;81:57-64.

20. Sherry B, Jefferds ME, Grummer-Strawn LM. Accuracy of adolescent self-report of height and weight in assessing overweight status: a literature review. Arch Pediatr Adolesc Med 2007;161:1154-61.

21. Connor Gorber S, Tremblay M, Moher D, Gorber B. A comparison of direct vs. self-report measures for assessing height, weight and body mass index: a systematic review. Obes Rev 2007;8:307-26. 